IJSE

41,3

182

Received 27 July 2012

Revised 24 April 2013

Accepted 29 April 2013

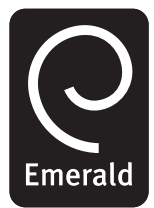

International Journal of Social Economics

Vol. 41 No. 3,2014

pp. $182-200$

(C) Emerald Group Publishing Limited 0306-8293

DOI 10.1108/IJSE-04-2012-0134

\section{Moon phase effect on investor psychology and stock trading performance}

\author{
Rayenda Brahmana, Chee-Wooi Hooy and Zamri Ahmad \\ School of Management, Universiti Sains Malaysia, Penang, Malaysia
}

\begin{abstract}
Purpose - This article aims to examine how investor moods and aggressiveness differ in their state and influence investor stock market performance associated with the moon phase. The mechanisms and impact of full moon gravity on investor stock trading performance are explored through an experimental approach and econometrics model.

Design/methodology/approach - A time-series quasi-experimental study, using the full moon and new moon time periods, was coupled with a psychometric test of investors' behaviours, administered through an online survey, similar to a pre-post experiment. Confirmation of the results was achieved by using an econometric model, adopted from Dichev and Janes.

Findings - This research found that investor psychology is influenced by the full moon, but no effect was recorded during the new moon phase. Confirmed by the paired $t$-difference test, the small correlation, in addition to the quantitative model, the results show the full moon impacts market behaviour during its orbital phase. Consequently, the authors surmise that the full moon does influence investor cognition and emotion disarray, mood disorders, and aggressiveness, resulting in poor stock trading performance.

Practical implications - The need for an active investment strategy is the major implication of this study. During the full moon phase, investors tend to be more aggressive and moody and seek hedonic utility instead of the traditional economics utility, meaning that they tend to follow the sentiment of the market. Originality/value - This paper fulfils an identified need to study how the full moon affects investor stock trading performance.
\end{abstract}

Keywords Environmental economics, Social economy

Paper type Research paper

\section{Introduction}

The effect of the moon's gravitation on human behaviour has been an issue of fascination for many years. Often called the "Transylvanian effect" (a psychology term to describe the role of moon on human activities), intense debate has surrounded research of its link to human behaviour. In the late 1970s, researchers Campbell and Beets (1978) concluded the Transylvanian effect was a Type 1 error, but this was later refuted by Garzino (1982) who countered that the finding of Campbell and Beet was a Type 2 error. In the end, Campbell (1982) surmised that the study of the moon effect should be stopped because regression of secondary data would not identify an effect of the moon on human behaviour.

However, the effect of full moon on financial markets was pioneered in a study by Dichev and Janes (2003); two decades after Campbell's (1982) paper. By using a moon phase dummy in a regression model, Dichev and Janes (2003) found a significant relationship between the occurrence of the full moon and market returns. However, secondary data was again used to conclude the effects of the moon on investor behaviour, even though this methodology had already been discounted ten years earlier. 